\title{
Identification of microRNAs associated with glioma diagnosis and prognosis
}

\author{
Xinyun $\mathrm{Ye}^{1, *}$, Wenjin Wei ${ }^{1, *}$, Zhengyu Zhang ${ }^{1, *}$, Chunming He ${ }^{1}$, Ruijin Yang ${ }^{1}$, Jinshi \\ Zhang ${ }^{1}$, Zhiwu Wu ${ }^{1}$, Qianliang Huang ${ }^{1}$, Qiuhua Jiang ${ }^{1}$ \\ ${ }^{1}$ Department of Neurosurgery, The Affiliated Ganzhou Hospital of Nanchang University, Ganzhou, Jiangxi 341000, China \\ *These authors have contributed equally to this work
}

Correspondence to: Qiuhua Jiang, email: jiangqh1968@163.com

Keywords: glioma, miRNA, diagnosis, prognosis, meta-analysis

Received: August 23, $2016 \quad$ Accepted: December 15, 2016

Published: January 02, 2017

Copyright: Ye et al. This is an open-access article distributed under the terms of the Creative Commons Attribution License (CC-BY), which permits unrestricted use, distribution, and reproduction in any medium, provided the original author and source are credited

\section{ABSTRACT}

The sensitivity and specificity of microRNAs (miRNAs) for diagnosing glioma are controversial. We therefore performed a meta-analysis to systematically identify glioma-associated miRNAs. We initially screened five miRNA microarray datasets to evaluate the differential expression of miRNAs between glioma and normal tissues. We next compared the expression of the miRNAs in different organs and tissues to assess the sensitivity and specificity of the differentially expressed miRNAs in the diagnosis of glioma. Finally, pathway analysis was performed using GeneGo. We identified 27 candidate miRNAs associated with glioma initiation, progression, and patient prognosis. Sensitivity and specificity analysis indicated miR-15a, miR-16, miR-21, miR23a, and miR-9 were up-regulated, while miR-124 was down-regulated in glioma. Ten signaling pathways showed the strongest association with glioma development and progression: the p53 pathway feedback loops 2, Interleukin signaling pathway, Toll receptor signaling pathway, Parkinson's disease, Notch signaling pathway, Cadherin signaling pathway, Apoptosis signaling pathway, VEGF signaling pathway, Alzheimer disease-amyloid secretase pathway, and the FGF signaling pathway. Our results indicate that the integration of miRNA, gene, and protein expression data can yield valuable biomarkers for glioma diagnosis and treatment. Indeed, six of the miRNAs identified in this study may be useful diagnostic and prognostic biomarkers in glioma.

\section{INTRODUCTION}

MicroRNAs (miRNAs) are single stranded, endogenous, non-coding RNAs of approximately 22 nucleotides. The first miRNA was discovered in 1993 and named lin-4. This gene was found to control the timing of $C$. elegans larval development [1]. However, miRNAs were not recognized as a distinct class of biological regulators with conserved functions until the second miRNA, let-7, was identified in $2000[2,3]$. Since then, thousands of miRNAs have been identified in Homo sapiens. These molecules have diverse biological functions in glioma initiation and progression [4-8]. More than half of all miRNAs inhibit target gene expression by binding to complementary sequences in the 3' untranslated regions of mRNAs $[9,10]$. A single miRNA may have hundreds of mRNA targets, and a single gene may have hundreds of miRNA regulators. Approximately $30 \%$ of all protein-coding genes may be regulated by miRNAs.

Glioma is an extremely aggressive and lethal type of brain tumor that arises from glial cells [11-16]. Therefore, early diagnosis and treatment is critical. Dysregulation of miRNAs has been shown to promote tumorigenesis through inhibition of tumor suppressor genes or inappropriate activation of oncogenes [1726]. For example, miRNA-21 (miR-21) enhances the chemotherapeutic effects of taxol on human glioblastoma multiforme cells [27]. Zhang et al. identified nine miRNAs associated with survival in 82 glioblastoma patients [28]. Additionally, Piwecka et al. identified many new miRNAs that were differentially expressed in malignant glioma tissue, and Drusco et al. identified miRNAs that were 
differentially expressed in cerebrospinal fluid, which could be used to diagnose central nervous system malignancies [29, 30]. Along with recent advances in microRNA technology, the number of miRNAs with diagnostic and prognostic value has increased. These biomarkers could improve the rapid and accurate diagnosis of glioma [31]. Several studies have achieved conflicting results, which could be explained by differences in the miRNA profiling systems and analytic platforms used in the studies.

Although the expression of individual miRNAs may be useful for distinguishing between cancer types, the potential of miRNAs as biomarkers for glioma requires a systematic analysis of the existing data. Therefore, we performed a meta-analysis to determine whether specific miRNAs could differentiate between glioma and normal tissue, and whether these miRNAs could be used as diagnostic or prognostic biomarkers. Additionally, we investigated the genes and pathways targeted by these miRNAs.

\section{RESULTS}

\section{MiRNA expression profiling}

We downloaded glioma miRNA datasets from the Gene Expression Omnibus (GEO), a public database at the National Center for Biotechnology Information. We manually screened the studies to identify those that included miRNA arrays and false discovery rate (FDR) and fold-change (FC) calculations. Five studies met the inclusion criteria and were included in our metaanalysis (Table 1). All studies were published between 2012 and 2015. Three of the studies were performed in China, one was performed in the United States, and one was performed in Poland. A total of 147 glioma and 34 normal tissue samples were included in the meta-analysis. There were 68,362 miRNAs that were reported to be differentially expressed in glioma compared to normal tissue. The study details are shown in Table 1.

\section{Predictive value of miRNA expression in glioma}

Glioma histological subtypes are diagnosed pathologically. Because the datasets were collected using different platforms, the probe sequences were mapped to miRBase (http://www.mirbase.org) using BLAST tools to identify concordant miRNA names. To determine whether the expression of the miRNAs could be used to distinguish between glioma and control cases, we performed a metaanalysis of three primary datasets (GSE25631, GSE61710, and GSE62381). These datasets comprised the training cohort and contained 118 cancer and 24 control tissue samples. The validation cohort consisted of two additional miRNA datasets (GSE65626 and GSE44726). We analyzed miRNA expression profiles in these five glioma microarray datasets compared to normal controls. The
miRNAs that were differentially expressed in various tissues are shown in Table 2. Microarray datasets were normalized using a normalization algorithm in GeneSpring 13.0 (Agilent). Normalization removed batch effects. We identified 27 miRNAs that were differentially expressed between normal and malignant tissue (Figure 1). Of these miRNAs, miR-124, miR-128, miR-323-3p, miR-665, miR-127-5p, and miR-886-3p were down-regulated, while miR-21, miR-10b, miR-92b, miR-25, miR-193a-3p, miR106b, miR-23a, miR-19b, miR-105, miR-19a, miR-15b, miR-182, miR-16, miR-130b, miR-15a, miR-17, miR9, miR-424, miR-181a-2, let-7c, and 193a-5p were upregulated in glioma tissue.

\section{Sensitivity and specificity of differentially expressed miRNAs}

We obtained expression data for differentially expressed miRNAs in the liver, ovary, uterus, brain, and glioma tissue from the GEO database. We found that miR-15a, miR-16, miR-21, miR-23a, and miR-9 were upregulated while miR-124 was down-regulated in glioma compared to normal tissue (Table 2).

Interestingly, miR-124 and miR-9 were selectively expressed in neural tissues. The highest miR-124 expression was observed in the hippocampus followed by the cerebellum, cerebral cortex, and midbrain. Decreased miR-124 expression was observed in various types of glioma including neuroblastoma, astrocytoma, medulloblastoma, and glioblastoma (Figure 2A). Finally, the highest miR-9 expression was observed in glioblastoma and neuroblastoma, followed by astrocytoma and normal brain tissue (hippocampus and midbrain) (Figure 2B).

MiR-15a, miR-16, miR-21, and miR-23a are nonspecific miRNAs that are expressed in many tissues. The expression of $\mathrm{miR}-15 \mathrm{a}$ and $\mathrm{miR}-16$, which are primarily expressed in lymphocytes and monocytes, was higher in glioma compared to normal brain tissue (Figure 3A and 3B). MiR-21 was highly expressed in all cancer cells evaluated including hepatocellular carcinoma, ovarian cancer, lung cancer, and osteosarcoma. In contrast, low levels were observed in normal brain tissue (Figure 3C). The expression of miR-23a was higher in various cancer cells (e.g. glioma, HeLa, and breast cancer cells) compared to normal brain tissue (Figure 3D).

\section{MiRNA target prediction and functional analysis}

MiRNAs regulate various biological processes through inhibition of target gene expression. To identify potential miRNA target genes, we queried the three most popular computational databases, miRBase, microRNA, and TargetScan, to identify target genes reported in all three databases. We identified 1,204 genes predicted to be targeted by six miRNAs. We next performed gene 
Table 1: Glioma miRNA expression profiling data

\begin{tabular}{|c|c|c|c|c|c|c|}
\hline \multirow{2}{*}{$\begin{array}{l}\text { Author and } \\
\text { Accession Number }\end{array}$} & \multirow{2}{*}{ Institution } & \multirow[t]{2}{*}{$\begin{array}{c}\text { Total } \\
\text { samples }\end{array}$} & \multicolumn{2}{|c|}{ Sample information } & \multirow[t]{2}{*}{$\begin{array}{c}\text { MicroRNA } \\
\text { Number }\end{array}$} & \multirow[t]{2}{*}{ Year } \\
\hline & & & Normal & Glioma & & \\
\hline $\begin{array}{l}\text { Zhang W } \\
\text { GSE25631 }\end{array}$ & Capital Medical University, China & 87 & 5 & 82 & 1146 & 2012 \\
\hline $\begin{array}{l}\text { Chen W } \\
\text { GSE44726 }\end{array}$ & Nanjing Medical University, China & 12 & 6 & 6 & 62976 & 2013 \\
\hline $\begin{array}{l}\text { Piwecka M } \\
\text { GSE61710 }\end{array}$ & Warsaw University of Life Sciences, Poland & 17 & 5 & 12 & 909 & 2015 \\
\hline $\begin{array}{l}\text { Drusco A } \\
\text { GSE62381 }\end{array}$ & The Ohio State University, USA & 58 & 14 & 44 & 753 & 2015 \\
\hline $\begin{array}{l}\text { Yang J } \\
\text { GSE65626 }\end{array}$ & Capital Medical University, China & 6 & 3 & 3 & 2578 & 2015 \\
\hline
\end{tabular}

Table 2: Differential expression of miRNAs in various tissues

\begin{tabular}{|c|c|c|c|c|c|c|}
\hline Hsa-miRNA & Liver & Ovary & Uterus & Prostate & Brain & Glioma \\
\hline let-7c & 0.006 & 0.022 & 0.036 & 0.045 & 0.003 & 0.009 \\
\hline miR-10b & $<0.001$ & 0.003 & 0.005 & $<0.001$ & $<0.001$ & 0.002 \\
\hline miR-105 & $<0.001$ & 0.002 & $<0.001$ & $<0.001$ & $<0.001$ & 0.002 \\
\hline miR-106b & $<0.001$ & $<0.001$ & $<0.001$ & $<0.001$ & $<0.001$ & $<0.001$ \\
\hline miR-124 & $<0.001$ & $<0.001$ & $<0.001$ & $<0.001$ & 0.227 & $<0.001$ \\
\hline miR-127-5p & $<0.001$ & $<0.001$ & $<0.001$ & $<0.001$ & $<0.001$ & $<0.001$ \\
\hline miR-128 & $<0.001$ & $<0.001$ & $<0.001$ & $<0.001$ & $<0.001$ & $<0.001$ \\
\hline miR-130a & 0.002 & 0.001 & $<0.001$ & $<0.001$ & 0.001 & $<0.001$ \\
\hline miR-15a & 0.002 & 0.005 & 0.003 & 0.004 & 0.019 & 0.044 \\
\hline $\operatorname{miR}-15 b$ & 0.004 & 0.002 & 0.002 & 0.002 & $<0.001$ & 0.001 \\
\hline miR-16 & 0.034 & 0.044 & 0.036 & 0.056 & 0.048 & 0.127 \\
\hline miR-17 & 0.001 & $<0.001$ & 0.002 & $<0.001$ & $<0.001$ & $<0.001$ \\
\hline miR-181a & 0.005 & 0.007 & $<0.001$ & 0.002 & 0.027 & 0.027 \\
\hline miR-182 & 0.002 & $<0.001$ & 0.002 & $<0.001$ & $<0.001$ & 0.002 \\
\hline miR-19a & 0.003 & $<0.001$ & 0.002 & $<0.001$ & $<0.001$ & 0.003 \\
\hline mir-19b & $<0.001$ & 0.002 & $<0.001$ & 0.001 & 0.001 & 0.002 \\
\hline miR-193a-3p & 0.001 & $<0.001$ & $<0.001$ & 0.002 & $<0.001$ & 0.002 \\
\hline miR-193a-5p & 0.004 & 0.002 & $<0.001$ & $<0.001$ & $<0.001$ & $<0.001$ \\
\hline $\operatorname{miR}-21$ & 0.001 & 0.004 & 0.023 & 0.022 & 0.005 & 0.156 \\
\hline $\operatorname{miR}-23 a$ & 0.001 & 0.005 & 0.007 & 0.008 & 0.001 & 0.037 \\
\hline $\operatorname{miR}-25$ & 0.001 & 0.001 & 0.003 & 0.002 & $<0.001$ & 0.003 \\
\hline miR-323-3p & $<0.001$ & $<0.001$ & $<0.001$ & $<0.001$ & $<0.001$ & $<0.001$ \\
\hline miR-424 & $<0.001$ & $<0.001$ & $<0.001$ & $<0.001$ & $<0.001$ & $<0.001$ \\
\hline miR-665 & 0.001 & $<0.001$ & $<0.001$ & $<0.001$ & 0.001 & $<0.001$ \\
\hline miR-886-3p & $<0.001$ & 0.002 & $<0.001$ & $<0.001$ & 0.001 & $<0.001$ \\
\hline miR-9 & 0.004 & 0.002 & 0.002 & 0.001 & 0.204 & 0.263 \\
\hline miR-92b & 0.004 & 0.003 & 0.002 & 0.002 & 0.001 & 0.002 \\
\hline
\end{tabular}




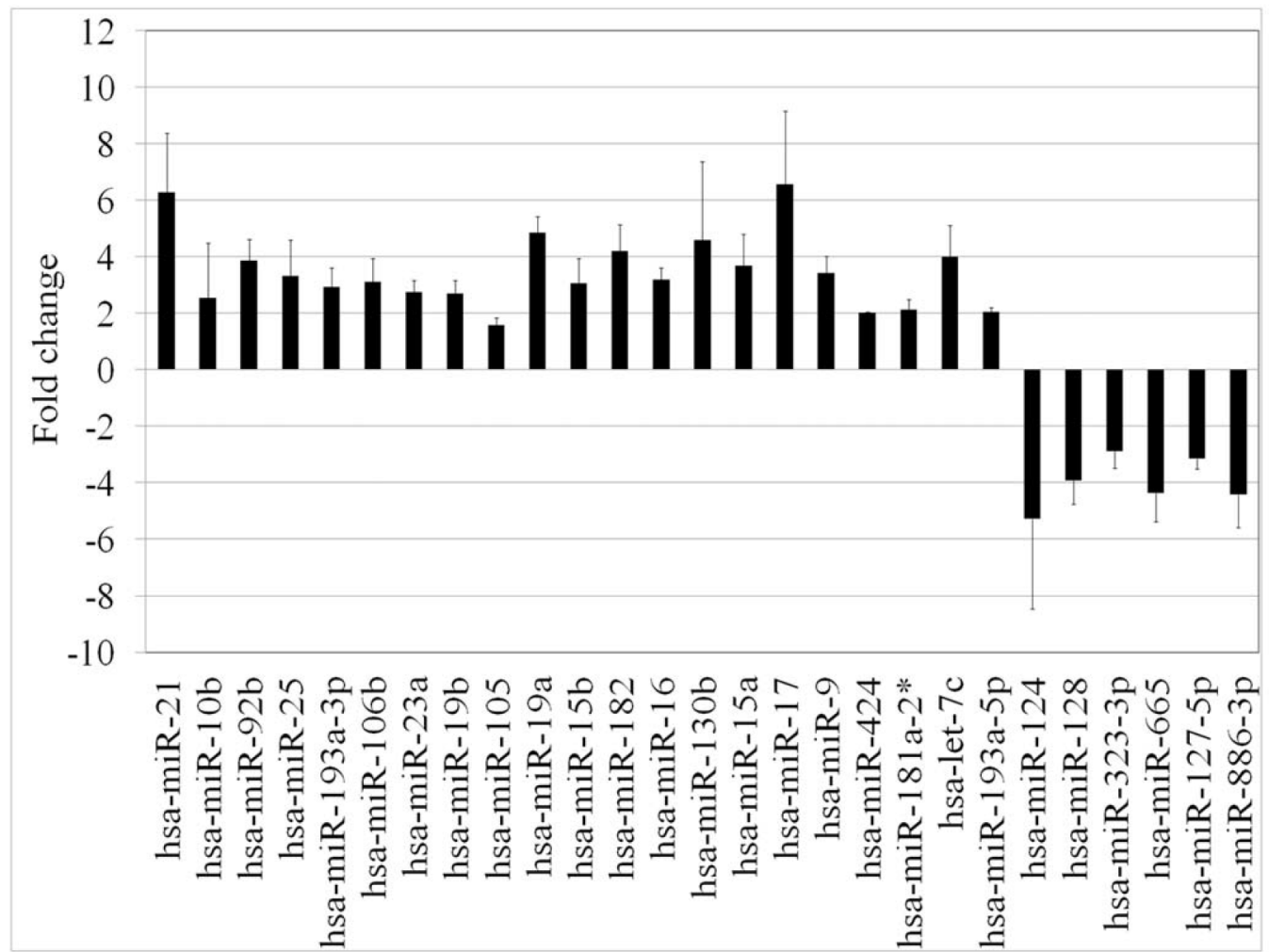

Figure 1: Meta-analysis of differentially expressed miRNAs. A total of 27 miRNAs were differentially expressed between glioma and normal tissue. Of these miRNAs, 21 were up-regulated and six were down-regulated.

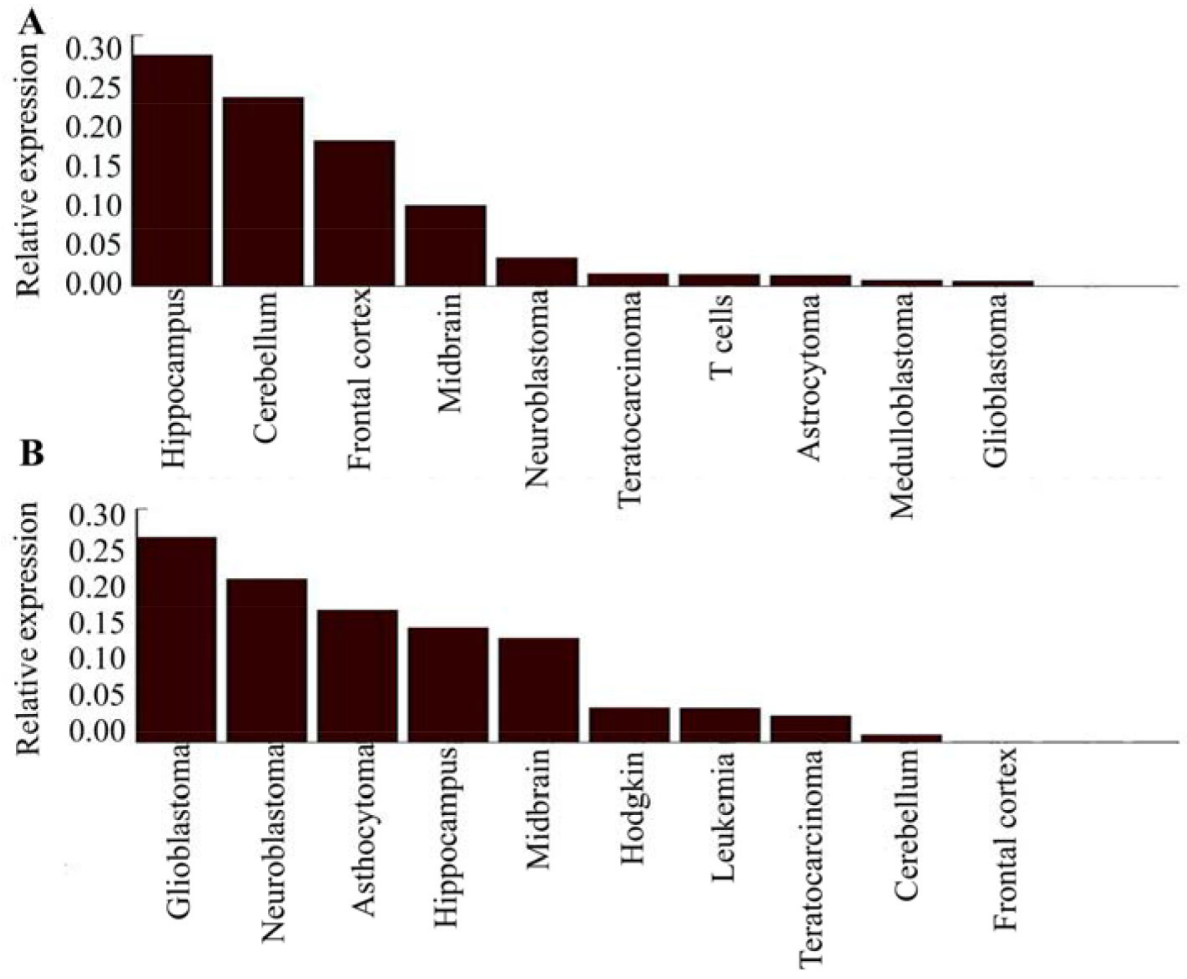

Figure 2: Relative expression of miR-124 (A) and miR-9 (B) compared to GAPDH in various tissues. The highest miR-124 expression is observed in the hippocampus followed by the cerebellum, cerebral cortex, and midbrain. The expression is lower in various types of glioma. Higher miR-9 expression is observed in glioblastoma and neuroblastoma tissue compared to normal and astrocytoma tissue. 
ontology (GO) analysis in order to define the biological functions of the target genes in a broad range of biological processes (e.g. catalytic activity, enzyme regulatory activity, nucleic acid-binding transcription factor activity, protein-binding transcription factor activity, receptor activity, structural molecule activity, and transporter activity) (Figure 4).

We performed KEGG pathway analysis of the target genes in various tissues. The top 10 pathways identified were the following: the p53 pathway feedback loops 2 , Interleukin signaling pathway, Toll receptor signaling pathway, Parkinson disease, Notch signaling pathway, Cadherin signaling pathway, Apoptosis signaling pathway, VEGF signaling pathway, Alzheimer disease-amyloid secretase pathway, and the FGF signaling pathway. These 10 pathways were highly associated with glioma initiation and progression (Table 3 ).

\section{DISCUSSION}

In our study, we used publicly available miRNA datasets to evaluate whether specific miRNAs may be

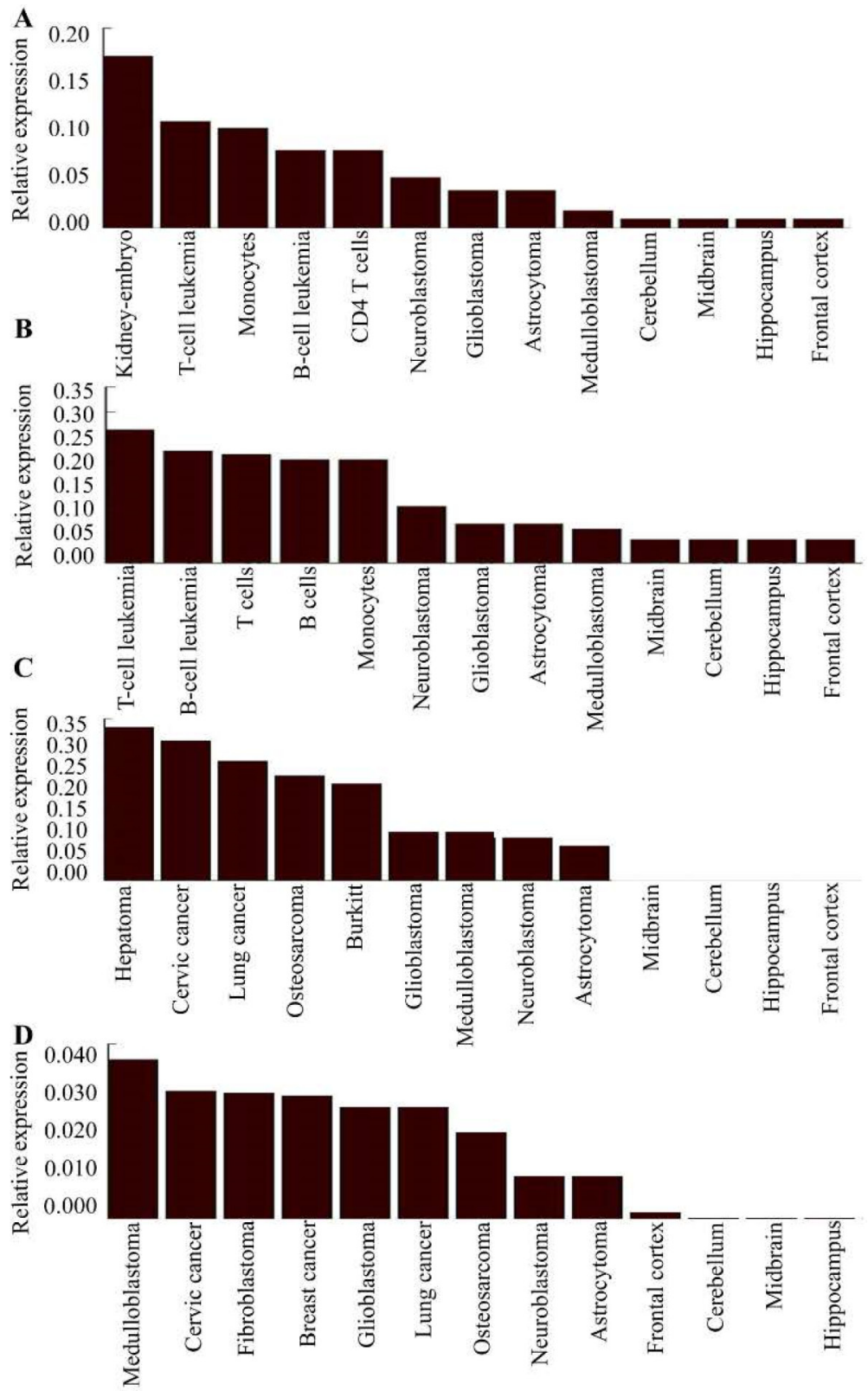

Figure 3: Relative expression of miR-15a (A) miR-16 (B) miR-21 (C) and miR-23a (D) compared to GAPDH in various tissues. MiR$15 \mathrm{a}$ and miR-16 are predominantly expressed in lymphocytes and monocytes. MiR-21 is highly expressed in various types of cancer cells including hepatocellular carcinoma, HeLa, lung, and osteosarcoma cells. The expression of miR-23a is increased in various types of cancers including glioma, HeLa, and breast cancer cells. 
useful and accurate biomarkers for discriminating between glioma and normal tissue. We selected five microarray datasets and systematically identified promising miRNAs that could distinguish between glioma and control tissue. We found that 27 microRNAs were differentially expressed between glioma and normal tissue. Six of these microRNAs had more accurate predictive value in distinguishing glioma from control tissue (i.e. higher sensitivity, higher specificity, and statistical significance.

The expression patterns and functions of various miRNAs in glioma are diverse. Some miRNAs such as miR-124 and miR-9 are specifically expressed in the brain. MiR-124, which is highly expressed in the central nervous system including the hippocampus, cerebellum, cerebral cortex, and midbrain, stimulates neuronal differentiation to maintain embryonic stem cell selfrenewal and pluripotency [32]. In high-grade malignant gliomas and astrocytomas, miR-124 was either minimally expressed or absent. Loss of miR-124 enhances the stemlike traits and invasiveness of glioma cells [32, 33]. Cai et al. found that down-regulation of miR-124 resulted in an increase in phosphorylated FAK, MMP2, vimentin, and N-cadherin levels in U87 cells through CAPN4, and that miR-124 suppressed the migration and invasion of glioma cells in vitro via CAPN4 [34]. Lu et al. reported that miR-124 inhibited glioma cell proliferation and invasion by blocking IQGAP1 expression and downstream activation of $\beta$-catenin and cyclin D1 [35]. Shi et al. demonstrated that down-regulation of miR-124 in tumor tissue promoted glioma development, angiogenesis, and chemoresistance, suggesting that miR-124 may be a useful diagnostic marker and therapeutic target in glioma [36]. Interestingly, miR-124 inhibited the migration and invasion of glioma cells through down-regulation of ROCK1, SOS1, CDK4, STAT3, and PPP1R13L expression [37-40], indicating miR-124 may be a valuable biomarker for glioma. The brain-enriched miR-9 also has been implicated in nervous system development and other physiological and pathological processes in several organisms. Increased expression of miRNA-9 was associated with an unfavorable prognosis in human glioma [41]. However, other studies have presented conflicting results. For example, suppression of miRNA-9 by mutant EGFR signaling resulted in up-regulation of FOXP1 and enhanced glioblastoma tumorigenicity [42-43].

Some of the miRNAs are not brain-specific. We found that miR-15a, miR-16, miR-21, and miR-23 were highly expressed in various cancer tissues including glioma. MiRNAs can also function as tumor suppressors. For example, Xie et al. demonstrated that down-regulation of miR-15a was associated with an adverse prognosis in human glioma patients [44]. Yang et al. validated the role of miR-16 as a tumor suppressor in glioma and uncovered a novel mechanism of miR-16-mediated inhibition of glioma growth and invasiveness through inhibition of BCL2 and the NF-кB1/MMP-9 signaling pathway [45, 46]. These results indicate that increased expression of miR-15a and miR-16 is protective against glioma. Some miRNAs may be oncogenic. For example, miR-23a promoted the invasion of U251 and U87 cells, at least in part by directly targeting HOXD10 and modulating the expression of MMP-14 [47, 48]. Moreover, the oncogenic miR-23a promotes glioma development through the cAMP response element-binding protein [49].

MiR-21 is one of the most well-studied miRNAs. It is over-expressed in various cancer tissues. Here,

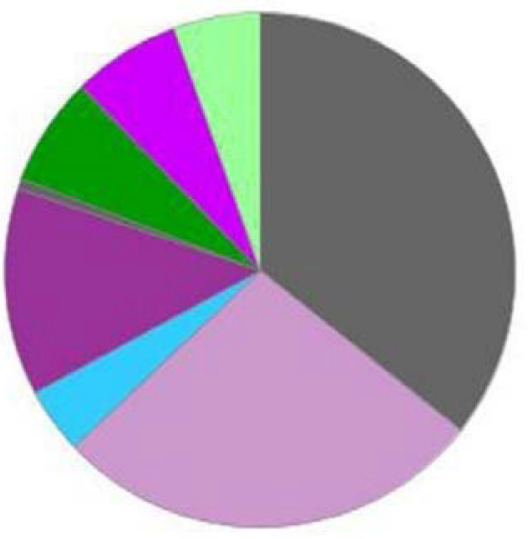

binding ( $\mathrm{GO}: 0005488)$

catalytic activity (GO:0003824)

enzyme regulator activity (GO:0030234)

nucleicacid binding transcription factor activity(GO:0001071)

protein binding transcription factor activity (GO:0000988)

receptor activity (GO:0004872)

- structural molecule activity (GO:0005198)

transporter activity (GO:0005215)

Figure 4: GO analysis of target gene functions. 
Table 3: The top 10 enriched pathways based on GeneGO analysis

\begin{tabular}{lcc}
\hline Pathways & Components & -log (p-value) \\
\hline p53 pathway feedback loops 2 & 32 & 10.1 \\
Interleukin signaling pathway & 36 & 7.16 \\
Toll receptor signaling pathway & 46 & 5.33 \\
Parkinson disease & 37 & 5.31 \\
Notch signaling pathway & 23 & 5.30 \\
Cadherin signaling pathway & 16 & 5.24 \\
Apoptosis signaling pathway & 72 & 5.16 \\
VEGF signaling pathway & 25 & 5.03 \\
Alzheimer disease-amyloid secretase pathway & 31 & 4.55 \\
FGF signaling pathway & 26 & 4.37 \\
\hline
\end{tabular}

we found that miR-21 expression was increased in several malignant cell types (particularly hepatocellular carcinoma cells). Dysregulated miR-21 expression was observed in all types of glioma. The oncogenic miR21 inhibits the tumor suppressive activity of FBXO11 to promote tumorigenesis [50-54]. Moreover, miR-21 promotes glioblastoma initiation through down-regulating IGFBP3 [55]. Additionally, miR-21 was shown to downregulate the expression of the tumor suppressor PDCD4 in the human glioblastoma cell line T98G [56]. Plasma miR-21 concentration may be a useful biomarker in glioblastoma patients [57]. The oncogenic miRNAs miR-21 and miR-23a are potential therapeutic targets in glioma.

To explore the interactions between miRNAs and their corresponding target genes, we performed pathway analyses using the list of target genes referenced by all three computational databases. The top 10 significant pathways showed enrichment of 2,104 genes associated with cancer initiation and progression. These genes represented a wide range of biological processes. We took advantage of statistical tools to mine available data for each target gene. We found that the FDR and FC values for more than half of the target genes met our criteria.

Our results demonstrate that a combination of miRNA and target gene expression could enable the identification of promising biomarkers for glioma and provide novel insights into the molecular mechanisms responsible for glioma initiation and progression. Additional studies are required to validate the impact of the six miRNAs on glioma development, progression, and patient prognosis.

\section{MATERIALS AND METHODS}

\section{Search strategies}

A two-phase literature search was performed to identify studies involving glioma miRNA expression profiling. First, microarray datasets were extracted from the NCBI and GEO databases using the following MESH terms: (microRNA OR miRNA) AND (brain carcinoma or brain cancer or brain tumor or brain neoplasm or glioma or glioblastoma) AND (expression OR profile OR profiling). Next, references from the included studies were manually screened to identify additional relevant studies. Three reviewers independently extracted the data from all eligible studies. All sample datasets (i) were from humans, (ii) included miRNA arrays, and (iii) were part of studies that included FDR and FC calculations. The datasets analyzed in this study are summarized in Table 1.

\section{Data collection and processing}

We collected five publicly available glioma microRNA microarray datasets that were assembled using different platforms. Each of the datasets was generated by a separate laboratory. To obtain more consistent results, we performed a meta-analysis of the multiple miRNA microarrays. The microarray datasets were analyzed based on the same statistical hypothesis (cancer versus normal tissue). We converted log2-transformed datasets from the different platforms into FC. A 5\% FDR in Bayesian statistical analysis was then used to identify statistically significant differences in miRNA expression between cancer and control cases.

\section{Sensitivity and specificity of differentially expressed miRNAs}

We analyzed publicly available expression data for miRNAs in various human tissues including the liver, ovary, uterus, prostate, and brain. We first collected data for miRNAs that were differentially expressed in these tissues, and then compared the expression to that observed in glioma tissue. The data were obtained from miRBase (www.mirbase.org), microRNA (www.microrna.org/ microrna/home.do), and RNAhybrid (bibiserv2.cebitec. uni-bielefeld.de/rnahybrid). The SPSS statistical software was used analyze the diagnostic value of miRNAs that 
were differentially expressed between glioma and normal tissue.

\section{MiRNA target prediction and functional analysis}

To identify potential miRNA target genes, we first queried the three most popular computational databases, miRBase [58], microRNA [59], and TargetScan [60]. We identified target genes that were present in all 3 databases. GO analysis of the potential target genes was based on the terms of the Gene Ontology database: gene functionrelated biological processes were detected, and genes with similar functions were combined. KEGG pathway analysis was performed to identify the pathways that were significantly associated with the target gene candidates based on a comparison with the entire set of reference genes. Target genes with a FDR $\leq 0.05$ were considered to be significantly enriched.

\section{CONFLICTS OF INTEREST}

The authors declare that there are no conflicts of interest.

\section{FUNDING}

This study was supported by a grant from the Natural Science Foundation of Jiangxi Province (No. 20122BAB205062).

\section{REFERENCES}

1. Lee RC, Feinbaum RL, Ambros V. The C. elegans heterochronic gene lin-4 encodes small RNAs with antisense complementarity to lin-14. Cell. 1993; $75: 843-854$

2. Reinhart BJ, Slack FJ, Basson M, Pasquinelli AE, Bettinger JC, Rougvie AE, Horvitz HR, Ruvkun G. The 21-nucleotide let-7 RNA regulates developmental timing in Caenorhabditis elegans. Nature. 2000; 403:901-906.

3. Bugide S, Manavathi B. Engagement, reception and breakup: Three steps of cell motility regulated by HPIP signaling. Can Cell Microenviron. 2015; 2:e660.

4. Sakr M, Takino T, Sabit H, Nakada M, Li Z, Sato H. miR150-5p and miR-133a suppress Glioma cell proliferation and migration through targeting membrane-type-1 matrix metalloproteinase. Gene. 2016; 587:155-162.

5. Ivo D'Urso P, Fernando D'Urso O, Damiano Gianfreda C, Mezzolla V, Storelli C, Marsigliante S. miR-15b and miR21 as Circulating Biomarkers for Diagnosis of Glioma. Curr Genomics. 2015; 16:304-311.

6. Hong L, Ya-Wei L, Hai W, Qiang Z, Jun-Jie L, Huang A, Song-Tao Q, Yun-Tao L. MiR-519a functions as a tumor suppressor in Glioma by targeting the oncogenic STAT3 pathway. J Neurooncol. 2016; 128:35-45.
7. Ye XY, Yang RJ, Zhang ZY, Jiang QH. MicroRNAs as regulators of connexin-43 expression. Can Cell Microenviron. 2016; 3:e1238.

8. Ye XY, Zhang ZY, Yang RJ, Jiang QH. Mechanisms of miRNA expression in regulating Glioma invasion. Can Cell Microenviron. 2016; 3:e1237.

9. Aghanoori MR, Mirzaei B, Tavallaei M. MiRNA molecular profiles in human medical conditions: connecting lung cancer and lung development phenomena. Asian Pac J Cancer Prev. 2014; 15:9557-9565.

10. Hirano $\mathrm{T}$. The role of the CCDC26 long noncoding RNA as a tumor suppressor. RNA Dis. 2016; 3:e1022.

11. Molinaro AM, Wrensch MR, Jenkins RB, Eckel-Passow JE. Statistical considerations on prognostic models for Glioma. Neuro Oncol. 2016; 18:609-623.

12. Ranjit M, Motomura K, Ohka F, Wakabayashi T, Natsume A. Applicable advances in the molecular pathology of glioblastoma. Brain Tumor Pathol. 2015; 32:153-162.

13. Cardama GA, Menna PL. Dynamic interaction between Glioma cells and their microenvironment: targeting Rac 1 as a therapeutic approach. Can Cell Microenviron. 2015; 2:e866.

14. Tang WC, Lee KH. Inhibitory effects of Berberine on the migratory and invasive abilities of cancer cells. Can Cell Microenviron. 2015; 2:e710.

15. Blacher E, Levy A, Baruch BB, Green KD, GarneauTsodikova S, Fridman M, Stein R. Targeting CD38 in the tumor microenvironment: a novel approach to treat Glioma. Can Cell Microenviron. 2015; 2:e486.

16. Kondo $\mathrm{T}$. Targeting the glioblastoma-initiating cellassociated antigens. Can Cell Microenviron. 2016; 3:e1329.

17. Xia X, Li Y, Wang W, Tang F, Tan J, Sun L, Li Q, Sun L, Tang B, He S. MicroRNA-1908 functions as a glioblastoma oncogene by suppressing PTEN tumor suppressorpathway. Mol Cancer. 2015; 14:154.

18. Jiang L, Wang C, Lei F, Zhang L, Zhang X, Liu A, Wu G, Zhu J, Song L. miR-93 promotes cell proliferation in Gliomas through activation of PI3K/Akt signaling pathway. Oncotarget. 2015; 6:8286-8299. doi: 10.18632/ oncotarget.3221.

19. Du W, Liu X, Chen L, Dou Z, Lei X, Chang L, Cai J, Cui Y, Yang D, Sun Y, Li Y, Jiang C. Targeting the SMO oncogene by miR-326 inhibits Glioma biological behaviors and stemness. Neuro Oncol. 2015; 17:243-253.

20. Wang JJ, Zeng QH, Yi CH, Luo J, Tang NN, Wang SH, Chen J, Cao K, Zhou JD. The biological function of microRNA195 and its relationship with angiogenesis. RNA Dis. 2015; 2:e610.

21. Wang CH, Chen Z and Ye ZQ. Small RNAs inhibit bladder cancer by up-regulating tumor suppressor genes. RNA Dis. 2015; 2:e595.

22. Ciafre SA, Galardi S, Mangiola A, Ferracin M, Liu CG, Sabatino G, Negrini M, Maira G, Croce CM, Farace MG. Extensive modulation of a set of microRNAs in primary 
glioblastoma. Biochem Biophys Research Comm. 2005; 334:1351-1358.

23. Chan JA, Krichevsky AM, Kosik KS. MicroRNA-21 is an antiapoptotic factor in human glioblastoma cells. Cancer Res. 2005; 65:6029-6033.

24. Silber J, Lim DA, Petritsch C, Persson AI, Maunakea AK, Yu M, Vandenberg SR, Ginzinger DG, James CD, Costello JF, Bergers G, Weiss WA, Alvarez-Buylla A, et al. miR124 and miR-137 inhibit proliferation of glioblastoma multiforme cells and induce differentiation of brain tumor stem cells. BMC Med. 2008; 6:14.

25. Godlewski J, Nowicki MO, Bronisz A, Williams S, Otsuki A, Nuovo G, Raychaudhury A, Newton HB, Chiocca EA, Lawler S. Targeting of the Bmi-1 oncogene/ stem cell renewal factor by microRNA-128 inhibits Glioma proliferation and self-renewal. Cancer Res. 2008; 68:9125-9130.

26. Rao SA, Santosh V, Somasundaram K. Genome-wide expression profiling identifies deregulated miRNAs in malignant astrocytoma. Mod Pathol. 2010; 23:1404-1417.

27. Ren Y, Zhou X, Mei M, Yuan XB, Han L, Wang GX, Jia $\mathrm{ZF}, \mathrm{Xu} \mathrm{P}, \mathrm{Pu} \mathrm{PY}$, Kang CS. MicroRNA-21 inhibitor sensitizes human glioblastoma cells U251 (PTEN-mutant) and LN229 (PTEN-wild type) totaxol. BMC Cancer. 2010; 10:27.

28. Zhang W, Zhang J, Hoadley K, Kushwaha D, Ramakrishnan V, Li S, Kang C, You Y, Jiang C, Song SW, Jiang T, Chen CC. miR-181d: predictive glioblastoma biomarker that downregulates MGMT expression. Neuro Oncol. 2012; 14:712-719.

29. Piwecka M, Rolle K, Belter A, Barciszewska AM, Żywicki M, Michalak M, Nowak S, Naskręt-Barciszewska MZ, Barciszewski J. Comprehensive analysis of microRNA expression profile in malignant Glioma tissues. Mol Oncol. 2015; 9:1324-1340.

30. Drusco A, Bottoni A, Laganà A, Acunzo M, Fassan M, Cascione L, Antenucci A, Kumchala P, Vicentini C, Gardiman MP, Alder H, Carosi MA, Ammirati M, et al. A differentially expressed set of microRNAs in cerebrospinal fluid (CSF) can diagnose CNS malignancies. Oncotarget. 2015; 6:20829-20839. doi: 10.18632/ oncotarget.4096.

31. Morimoto K and Tanaka T. Association NEDD9 with TGF$\beta$-triggered epithelial-mesenchymal transition and cell invasion in prostate cancer cells: implications for cancer aggressiveness. Can Cell Microenviron. 2015; 2:e342.

32. Xia H, Cheung WK, Ng SS, Jiang X, Jiang S, Sze J, Leung GK, Lu G, Chan DT, Bian XW, Kung HF, Poon WS, Lin MC. Loss of brain-enriched miR-124 microRNA enhances stem-like traits and invasiveness of Gliomacells. J Biol Chem. 2012; 287:9962-9971.

33. Li YJ, Zhu YH, Prochownik EV. MicroRNA-based screens for synthetic lethal interactions with c-Myc. RNA Dis. 2016; 3:e1330.
34. Cai JJ, Qi ZX, Chen LC, Yao Y, Gong Y, Mao Y. miR124 suppresses the migration and invasion of Glioma cells in vitro via Capn4. Oncol Rep. 2016; 35:284-290.

35. Lu SH, Jiang XJ, Xiao GL, Liu DY, Yuan XR. miR-124a restoration inhibits Glioma cell proliferation and invasion by suppressing IQGAP1 and $\beta$-catenin. Oncol Rep. 2014; 32:2104-2110.

36. Shi Z, Chen Q, Li C, Wang L, Qian X, Jiang C, Liu X, Wang X, Li H, Kang C, Jiang T, Liu LZ, You Y, et al. MiR-124 governs Glioma growth and angiogenesis and enhances chemosensitivity by targeting R-Ras and N-Ras. Neuro Oncol. 2014; 16:1341-1353.

37. An L, Liu Y, Wu A, Guan Y. microRNA-124 inhibits migration and invasion by down-regulating ROCK1 in Glioma. PLoS One. 2013; 8:e69478.

38. Lv Z, Yang L. MiR-124 inhibits the growth of glioblastoma through the downregulation of SOS1. Mol Med Rep. 2013; 8:345-349.

39. Wei J, Wang F, Kong LY, Xu S, Doucette T, Ferguson SD, Yang Y, McEnery K, Jethwa K, Gjyshi O, Qiao W, Levine NB, Lang FF, et al. miR-124 inhibits STAT3 signaling to enhance $\mathrm{T}$ cell-mediated immune clearance of Glioma. Cancer Res. 2013; 73:3913-3926.

40. Zhao WH, Wu SQ, Zhang YD. Downregulation of miR124 promotes the growth and invasiveness of glioblastoma cells involving upregulation of PPP1R13L. Int J Mol Med. 2013; 32:101-107.

41. Wu Z, Wang L, Li G, Liu H, Fan F, Li Z, Li Y, Gao G. Increased expression of microRNA-9 predicts an unfavorable prognosis in human Glioma. Mol Cell Biochem. 2013; 384:263-268.

42. German G. Gomez, Stefano Volinia, Carlo M. Croce, Ciro Zanca, Ming Li, Ryan Emnett, David H. Gutmann, Cameron W. Brennan, Frank B. Furnari, Webster K Cavenee. Suppression of MicroRNA-9 by Mutant EGFR Signaling Upregulates FOXP1 to Enhance Glioblastoma Tumorigenicity. Cancer Res. 2014; 74: 1429-1439.

43. S. Duygu Selcuklu, Mark T. A. Donoghue, Kristina Rehmet, Matheus de Souza Gomes, Antoine Fort, Prasad Kovvuru, Mohan K. Muniyappa, Michael J. Kerin, Anton J. Enright, Charles Spillane. MicroRNA-9 Inhibition of Cell Proliferation and Identification of Novel miR-9 Targets by Transcriptome Profiling in Breast Cancer Cells. J Biol Chem. 2012; 287: 29516-29528.

44. Xie T, Liu P, Chen L, Chen Z, Luo Y, Chen X, Feng Y, Luo X. MicroRNA-15a down-regulation is associated with adverse prognosis in human Glioma. Clin Transl Oncol. 2015; 17:504-510.

45. Yang TQ, Lu XJ, Wu TF, Ding DD, Zhao ZH, Chen GL, Xie XS, Li B, Wei YX, Guo LC, Zhang Y, Huang YL, Zhou YX, et al. MicroRNA-16 inhibits Glioma cell growth and invasion through suppression of BCL2 and the nuclear factor-кB1/MMP9 signaling pathway. Cancer Sci. 2014; 105:265-271. 
46. Lambert B, Meryet-Figuière M, Gauduchon P, Vigneron N, Brotin E, Poulain L, Denoyelle C. miRNAs as tools for tailoring personalized therapeutic strategies in ovarian carcinoma. RNA Dis. 2015; 2:e717.

47. Hu X, Chen D, Cui Y, Li Z, Huang J. Targeting microRNA23a to inhibit Glioma cell invasion via HOXD10. Sci Rep. 2013; 3:3423.

48. Bandopadhyay M, Chakravarty R. An insight into interaction of cell cycle regulating miRNAs and Hepatitis B virus X protein. RNA Dis. 2015; 2:e818.

49. Tan X, Wang S, Zhu L, Wu C, Yin B, Zhao J, Yuan J, Qiang B, Peng X. cAMP response element-binding protein promotes Gliomagenesis by modulating the expression of oncogenic microRNA-23a. Proc Natl Acad Sci U S A. 2012; 109:15805-15810.

50. Yang $\mathrm{CH}$, Pfeffer SR, Sims M, Yue J, Wang Y, Linga VG, Paulus E, Davidoff AM, Pfeffer LM. The oncogenic microRNA-21 inhibits the tumor suppressive activity of FBXO11 to promote tumorigenesis. J Biol Chem. 2015; 290:6037-6046.

51. Wu C and Wang QY. p53/microRNAs signaling in the pathological mechanism of Diabetic Kidney Disease. Inflamm Cell Signal. 2016; 3:e1132.

52. Kurata J, Lin RJ. TALEN-engineered human cell lines with microRNA-21 null mutations. RNA Dis. 2015; 2:e727.

53. Cai WP, Wang C, Goh JN, Loo SY, Yap CT, Kumar AP. DEAD-box RNA Helicases: the microRNA managers of breast cancer. RNA Dis. 2015; 2:e846.
54. Mathey-Andrews CA, Le MTN. Small but mighty: microRNAs as novel signalling molecules in cancer. RNA Dis. 2015; 2:e627.

55. Yang CH, Yue J, Pfeffer SR, Fan M, Paulus E, HosniAhmed A, Sims M, Qayyum S, Davidoff AM, Handorf CR, Pfeffer LM. MicroRNA-21 promotes glioblastoma tumorigenesis by down-regulating insulin-like growth factor-binding protein-3 (IGFBP3). J Biol Chem. 2014; 289:25079-25087.

56. Chen Y, Liu W, Chao T, Zhang Y, Yan X, Gong Y, Qiang B, Yuan J, Sun M, Peng X. MicroRNA-21 down-regulates the expression of tumor suppressor PDCD4 in human glioblastoma cell T98G. Cancer Lett. 2008; 272:197-205.

57. Ilhan-Mutlu A, Wagner L, Wöhrer A, Furtner J, Widhalm G, Marosi C, Preusser M. Plasma MicroRNA-21 concentration may be a useful biomarker in glioblastoma patients. Cancer Invest. 2012; 30:615-621.

58. Penso-Dolfin L, Swofford R, Johnson J, Alföldi J, Lindblad-Toh K, Swarbreck D, Moxon S, Di Palma F. An Improved microRNA Annotation of the Canine Genome. PLoS One. 2016; 11:e0153453.

59. Preusse M, Theis FJ, Mueller NS. miTALOS v2: Analyzing Tissue Specific microRNA Function. PLoS One. 2016; 11:e0151771.

60. Wang F, Lu J, Peng X, Wang J, Liu X, Chen X, Jiang Y, Li $\mathrm{X}$, Zhang B. Integrated analysis of microRNA regulatory network in nasopharyngeal carcinoma with deep sequencing. J Exp Clin Cancer Res. 2016; 35:17. 